\title{
EDUCAÇÃO PERMANENTE EM SAÚDE: REFLEXÕES DAS EXPERIÊNCIAS DE TRABALHADORES DE UM HOSPITAL PÚBLICO FRENTE AO PROCESSO DE MORTE E MORRER
}

\author{
Tiago Luan Labres de Freitas ${ }^{1}$ \\ Eleine Maestri ${ }^{2}$ \\ Denise Consuelo Moser ${ }^{3}$ \\ Pamela Karin Lazzaroto ${ }^{4}$
}

\begin{abstract}
RESUMO: O presente trabalho tem por objetivo relatar o desenvolvimento de uma prática extensionista acerca da vivência de profissionais da saúde com o processo de morte e morrer. A prática foi realizada com trabalhadores de um hospital do oeste catarinense, com o intuito de propiciar a troca de experiências e de percepções entre trabalhadores e acadêmicos de enfermagem sobre a temática. Durante o desenvolvimento das atividades, foram identificadas as fragilidades e as potencialidades do grupo, servindo como ponto crucial para o direcionamento das ações conforme a realidade vivencial nesta instituição. Com o decorrer da prática, foi possível contribuir para o desenvolvimento de concepções sobre o processo de morte e morrer dos profissionais e acadêmicos envolvidos, tornando-os mais sensíveis e mais preparados para o estabelecimento de relações efetivamente subjetivas e mais capazes para lidarem com as experiências que lhes são proporcionadas.
\end{abstract}

PALAVRAS-CHAVE: Aprendizagem. Experiência. Morte. Trabalhadores.

Continuous education in health: reflections about the experiences of hospital workers facing the death and dying process

\begin{abstract}
This study aims to report the development of an extension practice about the experience of health professionals in the process of death and dying. The practice was conducted with employees of a hospital in western Santa Catarina in order to facilitate the exchange of experiences and perceptions of workers and nursing students on the topic. During the development of the activities, the group's weaknesses and strengths were identified, which was crucial to direct the activities in accordance with the experiential reality at this institution. In the course of all activities, it was possible to contribute to the development of academic and professional conceptions about the process of death and dying, making people more sensitive and prepared to establish effectively subjective relationships and to know how to deal with the experiences that are provided.
\end{abstract}

KEYWORDS: Learning. Experience. Death. Workers.

\footnotetext{
Graduando em Enfermagem na Universidade Federal da Fronteira Sul (Campus Chapecó) (tiagolabres@hotmail.com).

2 Doutoranda em Enfermagem na Universidade Federal de Santa Catarina, professora assistente da Universidade Federal da Fronteira Sul (Campus Chapecó), bolsista FUMDES, coordenadora do Projeto de Extensão "Compartilhando Experiências do Processo de Morte e Morrer" (eleine.maestri@uffs.edu.br).

3 Doutoranda em Educação na Universidade Federal de Santa Catarina, professora assistente da Universidade Federal da Fronteira Sul (Campus Chapecó) (denise.moser@uffs.edu.br).

${ }^{4}$ Graduanda em Enfermagem na Universidade Federal da Fronteira Sul (Campus Chapecó) (pame_lazzaroto@hotmail.com).
} 


\section{INTRODUÇÃO}

A educação permanente das equipes do serviço de saúde constitui importante estratégia para desenvolver a reflexão crítica sobre as práticas. No entanto, para que haja um processo dialético entre os saberes dos profissionais e os da comunidade, é preciso que o projeto de educação permanente esteja orientado para a transformação do processo de trabalho, englobando as necessidades de aprendizagem das equipes com conhecimentos, habilidades, atitudes e valores da comunidade. A saúde requer que os profissionais "aprendam a aprender" e tornem suas práticas cuidadoras com o desenvolvimento de si, do coletivo e da instituição. As transformações oriundas da educação permanente objetivam a atuação crítica, propositiva, compromissada e tecnicamente competente (ARAÚJO; VIEIRA, 2004).

A educação permanente em saúde visa à geração de práticas que possibilitem a integração das ações individuais e coletivas, exigindo profissionais com visão sistêmica e integral do indivíduo, da família e da comunidade na qual ela está inserida. No âmbito da Enfermagem, representa uma concepção centrada na promoção da qualidade de vida dos profissionais atuantes no meio profissional da área da saúde (ARAÚJO; VIEIRA, 2004). Dessa forma, a educação permanente amplia as relações entre ensino e serviço e entre a docência e a atenção à saúde. É marcada pelo processo de aprendizagem no ambiente de trabalho, nos significados e na possibilidade de transformar a prática. Considera importante o conhecimento e experiências prévias dos trabalhadores e as necessidades de saúde das pessoas e populações atendidas (SOUSA et al., 2009).

Assim sendo, as necessidades de aprendizagem das equipes de saúde deverão coincidir com seus conhecimentos, habilidades, atitudes e valores, elementos essenciais para a resolução dos problemas identificados nas respectivas áreas. Nessa perspectiva, tem se preconizado que o processo educativo não deve ser considerado um momento particular da vida acadêmica, e sim, um investimento na formação para o trabalho, no qual ele possa definir as demandas educacionais (BRÊTAS; OLIVEIRA; YAMAGUTI, 2009). Nessa lógica, é importante trabalhar com a temática morte e morrer, por ser um tema com o qual as equipes de saúde se deparam constantemente no meio profissional e nem sempre se sentem preparados para lidar com a situação.

Em uma perspectiva empírica, muitas pessoas acreditam que a morte é uma ruína, ou uma passagem para o outro lado do cosmos, algo por qual todos vão passar um dia, mas que não sesabe quando e nem como (CECCIM, 2005).

O processo de morte e morrer aflora nos trabalhadores sentimentos de tristeza, fragilidade e impotência, desencadeando, na maioria das vezes, o distanciamento, manifestado em relações estritamente objetivas e insensíveis, sem espaço para a solidariedade e a fraternidade necessárias ao paciente e seus familiares nessa vivência. O profissional que convive com os sentimentos oriundos das vivências do tema em questão pode associar seu ambiente de trabalho a um local triste, sombrio, com emoções e sentimentos negativos. Assim, o medo gerado por essa experiência desencadeia mecanismos de defesa, como o distanciamento nas relações entre paciente e profissional. Essas manifestações configuram-se como uma proteção individual adotada pelos profissionais para enfrentarem o processo no seu cotidiano (BRÊTAS; OLIVEIRA; YAMAGUTI, 2009). 
No decorrer do ano de 2011, um hospital do oeste catarinense solicitou ao curso de graduação em Enfermagem da Universidade Federal da Fronteira Sul (UFFS) a inserção de docentes e discentes na instituição para a realização de atividades educativas aos trabalhadores. Entendemos que a educação permanente nas instituições de saúde não pode ficar sob a responsabilidade exclusiva do sistema de saúde e das respectivas instituições, mas deve ser compartilhada pelas instituições de ensino.

O Programa de Educação Permanente em Saúde proposto tem como objetivo central a transformação do processo de trabalho, orientando-o para uma constante melhoria da qualidade das ações e serviços de saúde. Diante da necessidade de aprimoramento nesses serviços, impõe-se o desenvolvimento de programas consistentes de educação permanente, voltados à superação dos problemas encontrados no cotidiano do exercício, com a inserção dos acadêmicos no universo profissional (ARAÚJO; VIEIRA, 2004).

Portanto, o processo de morte e morrer é inerente a todos os seres vivos. Nós, seres humanos, temos a consciência de que essa etapa perpassará o nosso caminhar, seja na experiência familiar ou pessoal (ARAÚJO; VIEIRA, 2004). Nesse hospital do oeste catarinense, existem as mesmas peculiaridades de tantas outras instituições relacionadas no processo de morte e morrer. Assim, o Programa de Educação Permanente em Saúde, por meio desta proposta, objetivou aproximar acadêmicos do curso de Enfermagem e trabalhadores do hospital para compartilharem experiências e percepções sobre o processo de morte e morrer.

\section{OBJETIVOS}

O objetivo do projeto foi identificar as fragilidades e potencialidades dos trabalhadores da saúde de um hospital de pequeno porte para a vivência do processo de morte e morrer. A partir da identificação das potencialidades, foram traçadas ações com os trabalhadores em prol da manutenção da qualidade do serviço hospitalar. A identificação das fragilidades subsidiou o desenvolvimento de ações, assegurando a qualidade de vida e o emocional dos trabalhadores.

\section{METODOLOGIA}

Trata-se de uma prática educativa em saúde desenvolvida, no período de março a dezembro de 2012, por acadêmicos do curso de Enfermagem da Universidade Federal da Fronteira Sul, Campus Chapecó, com 15 trabalhadores de um hospital público no oeste catarinense. Considerando que a vivência do processo de morte e morrer perpassa todos os setores, direta ou indiretamente, e que a instituição havia sinalizado a necessidade de integração entre os trabalhadores, a participação foi de caráter voluntário aos profissionais que se interessavam pela temática. Assim, o grupo foi composto por enfermeiros (2), técnicos de enfermagem (5), auxiliares administrativos/recepcionistas (3), farmacêutica (1), psicóloga (1) e responsáveis pela limpeza (3).

Para o desenvolvimento do projeto, foram propostas e executadas doze oficinas, fundamentadas 
na metodologia do Círculo de Cultura de Paulo Freire (1982), que ocorreram em horário de trabalho, com duração média de sessenta minutos.

A característica do Círculo é a constituição de um grupo de pessoas com interesse comum, que se reúnem, periodicamente, para refletir sobre temas geradores em suas realidades e situações de vida. Assim, o Círculo de Cultura se encaixa perfeitamente para a aplicabilidade desta atividade de extensão. As construções coletivas refletem percepções da realidade que geram como resultado a elaboração de estratégias concretas de intervenção (LINHARES, 2013).

No Círculo de Cultura, Freire aprofunda a questão, afirmando que o medo da liberdade, impresso nos oprimidos ao longo de sua vida, leva-os a assumir mecanismos de defesa e que, "através de racionalizações, escondem o fundamental, enfatizam o acidental e negam a realidade concreta" (FREIRE, 1982, p. 6). Sendo assim, a realidade dos serviços de saúde exemplifica a base freireana.

O ponto de partida é a busca e a investigação acerca do tema gerador: situações existenciais, concretas, que se encontram "codificadas" pela realidade, para então chegar à "descodificação", isto é, à "análise e consequente reconstituição da situação vivida: reflexo, reflexão e abertura de possibilidades concretas de ultrapassagem" (FREIRE, 1982, p. 6), ou ainda, uma proposta de reflexão que parte do abstrato até o concreto, uma ida das partes ao todo, sem se esquecer de uma volta do todo às partes. Tal processo levará ao reconhecimento do sujeito no objeto, ou seja, fará com que o homem perceba a sua situação existencial concreta e a sua historicidade. $\mathrm{O}$ universo, que antes era fechado, agora vai se abrindo a uma nova realidade (LINHARES, 2013).

Almejando um ambiente mais acolhedor, as oficinas foram desenvolvidas a partir de temas geradores do processo de morte e morrer. Constituíram-se de três momentos: dinâmica de integração/acolhimento, discussão da temática, seleção de estratégias/conclusões.

As atividades ocorreram na modalidade de curso e a execução prática do método foi dividida em cinco fases de elaboração, adaptadas para a temática:

$1^{\text {a }}$ fase: Conhecimento do universo vocabular do grupo a ser trabalhado; desse modo caracterizouse a equipe, mantendo um vínculo por meio de encontros formais, entrevista e observação. Nesta primeira fase, ocorreu a apresentação dos participantes e suas experiências e percepções acerca do processo de morte e morrer.

$2^{a}$ fase: Foram selecionadas algumas das palavras do universo vocabular dos participantes a partir de três critérios: da riqueza do tema; da dificuldade de compreensão e execução numa sequência gradativa dessas dificuldades; do teor pragmático, ou seja, na pluralidade de engajamento da palavra numa dada realidade social, cultural e política. A escolha das palavras/temas foi realizada pelo próprio grupo.

$3^{\mathrm{a}}$ fase: A criação de situações existenciais advindas do grupo trabalhado, chamadas de situaçãoproblema, desafiou o grupo para uma intervenção. Partindo dos temas selecionados, foi proposto que os participantes classificassem fragilidades e potencialidades no processo de morte e morrer.

$4^{\mathrm{a}}$ fase: Foram confeccionadas fichas-roteiro que nortearam a atividade, auxiliando o coordenador 
duranteodebateno gruposobreas fragilidades eas potencialidades noprocessodemorteemorrer.Assim, as discussões foram conduzidas partindo da realidade e com profundidade e embasamento teórico.

$5^{\mathrm{a}}$ fase: Os participantes realizaram uma revisão de seus conhecimentos e propuseram ações de cuidado para serem implementadas no cotidiano e transformarem sua prática.

\section{RESULTADOS E DISCUSSÃO}

Como ponto de partida, foram realizadas divulgações das oficinas por meio de sensibilização dos trabalhadores nos respectivos setores de atuação, por intermédio de cartazes fixados nos murais da instituição e de encontros com a equipe de educação em serviço. O reconhecimento prévio do campo, horários, distribuição de afazeres, horários de pico em cada setor, entre outros aspectos, foram necessários para a definição do cronograma e do planejamento das oficinas, de modo a assegurar a participação efetiva de todos.

Nas primeiras oficinas realizadas, instigamos a socialização de experiências prévias com o processo de morte e morrer no âmbito profissional e pessoal. Buscamos explorar o pensamento empírico que os trabalhadores possuíam sobre a temática e o compartilhamento das experiências apontando pontos positivos e negativos. Na sequência, foram apresentadas concepções científicas que caracterizavam o processo e suas fases - negação: o paciente evita falar sobre a doença; raiva: o paciente torna-se agressivo pelo fato de que vai morrer; barganha: o paciente tenta se apegar em algo para tentar escapar de seu destino; depressão: o paciente isola-se do mundo por sua doença não ter cura; aceitação: o paciente conforma-se com suas condições e assim tenta resolver pendências (SOUZA; SOUZA, SOUZA, 2005). Observamos que os trabalhadores do hospital, em sua maioria, vislumbram a morte como um percurso natural da vida e como algo inevitável.

Durante as oficinas, foram elencadas como potencialidades: aceitação da morte como algo natural da vida; respeito com o próximo e sua crença religiosa; conhecer o paciente e seu círculo familiar (por se tratar de uma cidade pequena, é de grande valia para a manutenção da assistência com qualidade); o cuidado de si como profissional, frente a essa peculiar temática que perpassa a vida de todos.

No que diz respeito às fragilidades, no decorrer das oficinas, o compartilhamento das experiências em grupo serviram para o remodelamento de concepções e atitudes perante a morte. De forma clara, pode-se observar que um profissional ao ver que outros, mesmo que de setor diferente, apresentam certas fragilidades e despreparo semelhantes ao seu, busca estímulo para que o enfrentamento desses obstáculos psicológicos ocorra de forma natural e humana.

Em cada oficina realizada, instigávamos a formulação de uma mentalidade aberta, pronta para enfrentar a morte como algo normal, mas sem deixar a frieza tomar conta do ambiente, pois os profissionais da saúde são o amparo das famílias neste momento.

No entanto, os profissionais manifestaram abertamente as dificuldades e o despreparo para uma vivência considerada tão complexa. Alguns aspectos foram citados como marcantes 
e desfavoráveis para essa experiência, como, por exemplo, o turno noturno e o fato de estarem sozinhos no ambiente. As inabilidades para a vivência do processo de morte e morrer foram elencadas como as principais a serem superadas. Nesse contexto, frisamos a importância desse preparo durante a graduação dos profissionais (KOVÁCS, 2010).

Cabe destacar que, em relação à morte e ao processo de morrer, cada sociedade tem seus próprios comportamentos, hábitos, crenças e atitudes, que oferecem aos indivíduos uma orientação de como devem se comportar e o que devem ou não fazer, refletindo a cultura própria de cada lugar e, também, diferenciando-a de outros (KOVÁCS, 2010).

Com as discussões abertas, percebe-se que, automaticamente, os funcionários criam uma barreira psicológica no relacionamento com os pacientes, uma forma de sofrerem menos caso esses pacientes venham a óbito. Muitos profissionais relatam sentimento de impotência e baixa autoestima quando perdem um paciente, mesmo sabendo que fizeram o que podiam. Assim, a maioria acaba criando um afastamento com o paciente, para não desenvolver sentimentos, caso ocorra o óbito. Essa barreira é o que atrapalha o trabalho humanizado. A resistência que os funcionários acabam por desenvolver pode parecer frieza para com o paciente e com a família, no entanto, sabe-se que isso é, na verdade, automático ao perfil psicológico do funcionário, caracterizando, assim, fragilidades de grande importância na execução da assistência (BRÊTAS; OLIVEIRA; YAMAGUTI, 2009).

Como se trata de um hospital de um município pequeno, os funcionários acabam conhecendo a maioria dos pacientes que ali chegam. Apesar disso, é inerente que, no meio profissional, certo afastamento ocorra devido ao medo de que essa pessoa possa ir a óbito. Muitos relatam sentirem-se estagnados em prestarem o cuidado com pessoas próximas, por medo da cobrança de explicações ou apontamento de falhas que possam vir da família após a morte do paciente.

Quando se trata do atendimento de pessoas do seu círculo familiar, relatam ser mais fácil a execução dos procedimentos e a aceitação de determinadas consequências. Muitos relatam experiências que envolveram seus familiares e que seu atendimento foi mais aberto e efetivo. Apontam, ainda, que é evidente que a presença contínua de um familiar ameniza a dor dos pacientes que se encontram debilitados (KOVÁCS, 2010).

Surgiram relatos sobre a experiência com familiares em fase terminal de câncer que optaram pela morte por causas naturais, sem interferência da ciência para o prolongamento da vida, mas sim prestando todos os cuidados para não haver o sofrimento físico e psicológico no enfermo (SUSAKI; SILVA; POSSARI, 2009). Como esses funcionários, em sua jornada profissional, já possuem certas concepções, servem de suporte para que o restante de sua família compreenda que, em determinado momento, nada mais se pode fazer, restando apenas a eles aproveitarem os últimos momentos com seu ente querido.

A fé representa, nesse aspecto, uma das fontes mais solicitadas pelos pacientes e familiares. Sendo assim, a presença de um religioso, abordando o significado da vida e da morte, segundo as necessidades e desejos dos pacientes, é considerada por eles um gesto de amor, de conforto e de compreensão (GUTIERREZ; CIAMPONE, 2007). E, ainda em relação ao lado religioso, os funcionários consideram e respeitam a crença de cada paciente e de seu familiar. 
É considerado mais penoso a esses profissionais se depararem com crianças envolvidas no processo de morte e morrer, demonstrando sentimento de revolta e sofrimento. A maioria tem mais dificuldade para aceitar a morte na infância, considerando-a como a interrupção de uma vida que não chegou a ser vivida na sua plenitude (KÜBLER-ROSS, 1996).

No que diz respeito à aceitação da morte, ficou claro que, quando se trata de uma criança com probabilidade de óbito, mostram-se mais tristes e fechados pelo fato de acreditarem que esse ser humano teria uma vida inteira pela frente. Quando ocorre o óbito de alguma criança ou jovem, os sentimentos de impotência e dor são mais intensos. Ao contrário, quando se trata de morte de uma pessoa idosa, mostram-se mais conformados pelo fato conceberem que o idoso já está na etapa final da vida. Certamente, deixam claro que fazem de tudo para que isso não ocorra e que realizam todos os procedimentos possíveis para que o enfermo não sofra, não distinguindo o cuidado entre os pacientes (CECCIM, 2005).

Nesse sentido, os profissionais deveriam contribuir para que os familiares e os indivíduos do convívio compreendam a doença, ao contrário de focalizar somente a saúde do paciente. Essa conscientização pode ajudar o paciente a enfrentar a sua enfermidade e até mesmo facilitar a conscientização da aproximação da morte (GUTIERREZ; CIAMPONE, 2007).

Como o processo morte e morrer é muito complexo e pouco trabalhado, os profissionais de saúde, principalmente os da Enfermagem, estão despreparados para lidar com questões a ele relacionadas. Na graduação, esse tema tende a ser considerado menos importante, já que a imagem de hospital vincula-se a local de cura, visto que é procurado por pessoas que têm a esperança de sair de lá curados (GUTIERREZ; CIAMPONE, 2007).

Durante as oficinas, ficou evidente o interesse dos participantes em adquirir novos conhecimentos e desenvolver habilidades para sua vida profissional e pessoal, habilidades que, certamente, os auxiliarão na construção de um ambiente de trabalho favorável e de qualidade.

\section{CONSIDERAÇÕES FINAIS}

A prática estabeleceu importante aproximação entre o ensino e o serviço, fortalecendo as relações e mostrando a função social da universidade. A proposta buscou assegurar um processo de discussão frente ao tema, no sentido de colocar luz sobre o foco no contexto da saúde, e visou contribuir para o aperfeiçoamento de concepções dos profissionais e acadêmicos sobre o processo de morte e morrer, de forma a torná-los mais sensíveis, próximos e preparados para o estabelecimento de relações efetivamente subjetivas.

No decorrer das atividades, ficou evidente a necessidade constante de trabalhar com temáticas que estão inseridas cotidianamente no campo profissional e que podem dificultar a execução de um trabalho de qualidade. Sendo assim, apontamos ser de total relevância a problematização da morte junto aos trabalhadores, explorando suas potencialidades e modificando suas fragilidades, para, assim, criar um ambiente de trabalho aconchegante e propício. 
Julgamos que o desenvolvimento das atividades seguindo o Círculo de Cultura foi uma estratégia de grande valia, pois aproximou os funcionários dos mais variados setores, de forma que todos puderam compartilhar anseios e ideias para trabalhar a temática, contribuindo, assim, para um ambiente saudável de trabalho.

Cada profissional desempenha um papel específico ao acompanhar o paciente. No entendimento, a partir do momento em que a morte se aproxima daquele que se encontra hospitalizado, é necessário que uma pessoa esteja ao lado do doente e que possa lhe oferecer assistência e um modo digno para seguir o seu destino. É, principalmente, o enfermeiro que, por permanecer mais tempo com esses pacientes, cuidando deles, é que frequentemente presenciam o ato de morrer, oferecendo um suporte à família, fragilizada neste momento (GUTIERREZ; CIAMPONE, 2007).

Nesse contexto, consideramos relevantes os estudos que possibilitem aos profissionais desenvolverem o autoconhecimento e realizarem intervenções que auxiliem na assistência dos pacientes e familiares diante do processo de morte e morrer, minimizando o seu próprio sofrimento psíquico e auxiliando no desenvolvimento de estratégias coletivas de enfrentamento. É importante apreender e compreender os valores subjacentes às diferentes representações sobre o processo em questão com o objetivo de resgatá-las e integrá-las ao modo de ser, pensar, sentir e agir que conferem significado à atuação profissional.

Assim, o Programa de Educação Permanente em Saúde, por meio desta prática, serviu para a construção de conhecimentos e para direcionar ações efetivas de integração dos profissionais perante a temática, de desenvolvimento de potencialidades e de remodelamentos de fragilidades como forma de cuidado ao paciente/família, trabalhadores e acadêmicos de Enfermagem durante a vivência do processo de morte e morrer dos pacientes.

\section{REFERÊNCIAS}

ARAÚJO, P. V. R.; VIEIRA, M. J. A questão da morte e do morrer. Revista Brasileira de Enfermagem, Brasília, v. 3, n. 57, p. 361-363, 2004.

BRÊTAS, J. R. S.; OLIVEIRA, J. R.; YAMAGUTI, L. Reflexões de estudantes de enfermagem sobre a morte e o morrer. Revista da Escola de Enfermagem da USP, São Paulo, v. 4, n. 40, p. 477-483, 2006.

CECCIM, R. B. Educação permanente em saúde: descentralização e disseminação de capacidade pedagógica na saúde. Ciência e Saúde Coletiva, Rio de Janeiro, v. 4, n. 10, p. 975-986, 2005.

FREIRE, P. Pedagogia do oprimido. 11. ed. Rio de Janeiro: Paz e Terra, 1982.

GUTIERREZ, B. A. O.; CIAMPONE, M. H. T. O processo de morrer e a morte no enfoque dos profissionais de enfermagem de UTIs . Revista da Escola de Enfermagem da USP, São Paulo, v. 41, n. 4, p. 660-667, 2007.

KOVÁCS, M. J. Sofrimento da equipe de saúde no contexto hospitalar: cuidando do cuidador profissional. O mundo da saúde, São Paulo, v. 34 n. 4, p. 420-429, 2010. 
KÜBLER-ROSS, E. Sobre a morte e o morrer: o que os doentes terminais têm para ensinas aos médicos, enfermeiros, religiosos e aos próprios parentes. 7. ed. São Paulo: Martins Fontes, 1996.

LINHARES, L. L. Paulo Freire: por uma educação libertadora e humanista. Disponível em: $<$ http://arquivo.geledes.org.br/component/rsfiles/view?path=Paulo_Freire/Paulo_Freire_por_ uma_educacao_libertadora_e_humanista.pdf >.Acesso em: 22 jun. 2013.

SOUSA, D. M. et al. A vivência da enfermeira no processo de morte e morrer dos pacientes oncológicos. Texto Contexto Enfermagem, Florianópolis, v. 1, n. 18, p. 41-47, 2009.

SOUZA, L. B.; SOUZA, L. E. E. M; SOUZA, A. M. A. A ética no cuidado durante o processo de morrer: relato de experiência. Revista Brasileira de Enfermagem, Brasília, v. 58, n. 6, p. 731-734, 2005.

SUSAKI, T. T.; SILVA, M. J. P.; POSSARI, J. F. Identificação das fases do processo de morrer pelos profissionais de enfermagem. Acta Paulista de Enfermagem, São Paulo, v. 2, n. 19, p.144-149, 2009.

Submetido em $1^{\circ}$ de novembro de 2013.

Aprovado em 19 de fevereiro de 2014. 